\title{
Comparative performance of two air samplers for monitoring airborne fungal propagules
}

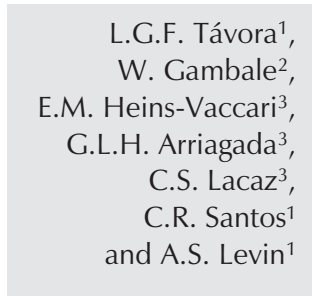

\author{
1Departamento de Moléstias Infecciosas, Hospital das Clínicas, \\ Faculdade de Medicina, Universidade de São Paulo, São Paulo, SP, Brasil \\ ${ }^{2}$ Laboratório de Micologia, Instituto de Ciências Biomédicas, and \\ ${ }^{3}$ Laboratório de Micologia Médica, Instituto de Medicina Tropical, \\ Universidade de São Paulo, São Paulo, SP, Brasil
}

\section{Correspondence \\ L.G.F. Távora \\ Rua Prof. Dias da Rocha, 482/34 \\ Meireles \\ 60170-310 Fortaleza, CE \\ Brasil \\ Fax: +55-11-3088-7095 \\ E-mail: laratavora@hotmail.com \\ L.G.F. Távora was the recipient of a FAPESP research fellowship.}

Received July 17, 2002 Accepted February 17, 2003

\begin{abstract}
Many studies have attempted to evaluate the importance of airborne fungi in the development of invasive fungal infection, especially for immunocompromised hosts. Several kinds of instruments are available to quantitate fungal propagule levels in air. We compared the performance of the most frequently used air sampler, the Andersen sampler with six stages, with a portable one, the Reuter centrifugal sampler (RCS). A total of 84 samples were analyzed, 42 with each sampler. Twenty-eight different fungal genera were identified in samples analyzed with the Andersen instrument. In samples obtained with the RCS only seven different fungal genera were identified. The three most frequently isolated genera in samples analyzed with both devices were Penicillium, Aspergillus and Cladophialophora. In areas supplied with a high efficiency particulate air filter, fungal spore levels were usually lower when compared to areas without these filters. There was a significant correlation between total fungal propagule measurements taken with both devices on each sampling occasion (Pearson coefficient $=0.50$ ). However, the Andersen device recovered a broader spectrum of fungi. We conclude that the RCS can be used for quantitative estimates of airborne microbiological concentrations. For qualitative studies, however, this device cannot be recommended.
\end{abstract}

The role of airborne fungi in the pathogenesis of respiratory illnesses in occupants of indoor environments has been increasingly recognized (1-3). Furthermore, many studies have attempted to evaluate the importance of fungal aerobiology in the acquisition of invasive fungal infection by immunocompromised patients (4-6). The difficulty in establishing a reliable method to measure exposure to respirable fungal particles is one
Key words

- Andersen sampler

- Reuter centrifugal sampler

- Air sampler

- Fungal contamination

- Indoor air

- Hospital air of the major barriers in clarifying the actual impact of exposure on the development of fungal infections. Airborne fungal spore concentration frequently varies depending on environmental temperature and relative air humidity, time of day, velocity and direction of winds, presence of human activity, and type of climatization (in indoor areas) (710). Several methods for measuring airborne fungal contaminants have been described 
(viable propagule sampling, nonviable propagule sampling, and measurement of a biochemical indicator of the presence of fungal propagules) (11-13). The use of air sampler devices is an efficient way to estimate viable fungal particle levels and, therefore, these devices have been frequently used. Many studies addressing the differences and efficiency of the various air samplers have been published (10,14-16). The N-6 Andersen sampler, a six-stage impactor, is the most widely recommended for sampling fungal propagules in indoor environments. However, its use may be limited because it is a noisy and heavy instrument which requires a continuous electrical power supply. The purpose of the present study was to perform a statistical comparison of the number and type of fungal propagules taken up by the N-6 Andersen sampler, which is considered to be the reference impactor, and the Reuter centrifugal sampler (RCS), which is a portable, battery supplied and easy to handle instrument.

The study was conducted at Hospital das Clínicas, School of Medicine, University of São Paulo, from October to December, 1999.

Air was sampled from six naturally ventilated areas (Renal Transplant Unit corridor, Hepatic Transplant Unit corridor and one patient's room, Hematology Ward corridor, Internal Medicine Ward corridor and an administrative area), four artificially ventilated areas (Hematology ICU, Internal Medicine ICU, Neonatal ICU and Burn Ward ICU), three artificially ventilated areas with a high efficiency particulate air (HEPA) filter (Bone Marrow Transplant Unit corridor and two patient's rooms) and the outdoor environment. Two samples (one with each sampling device) were obtained on three different days in the studied areas. The two samplers were placed side-by-side during the measurements. Air was collected for 20 min, approximately one meter above the floor, during the morning and always in the same place as the previous sampling.
The N-6 Andersen is a sieve-type impactor that collects airborne particles through six stages and also classifies these particles according to size. It requires a power supply and was calibrated at a flow rate of $28 \mathrm{l} / \mathrm{min}$. The RCS is a portable air sampler in which the fungal propagules are drawn into the device by a fan and impacted against a plastic strip containing specific culture medium. It was calibrated at a flow rate of $40 \mathrm{l} / \mathrm{min}$.

Sabouraud dextrose agar (Merck, Darmstadt, Germany) was used on the Andersen sampler plates and an agar strip containing specific medium for yeasts and molds (Agar strips YM) was used in the RCS. After air was sampled, the Andersen plates and the RCS strips were incubated at $25^{\circ} \mathrm{C}$ for 4 days. Fungal genera were identified by macroscopic observation of the colonies and by the microscopic characteristics of the sporulating hyphae determined by the Ridell technique (17). When no fungal sporulation was detected, colonies were subcultured in special media, i.e., potato agar, cornmeal agar or Czapek agar. If no fungal sporulation was identified, colonies were classified as Mycelia sterilia. The number of colony-forming units (cfu) was calculated as $\mathrm{cfu} / \mathrm{m}^{3}$ for the comparison of the two devices.

Statistical data analysis was performed using SPSS software. Means and SD were calculated. Means were compared using the Student $t$-test. As both the Andersen and the RCS data showed a normal distribution, correlation between the measurements of the two samplers was evaluated using the Pearson correlation coefficient.

A total of 84 samples were obtained, 42 with each sampler. Fungal spore levels (FSL) obtained with the Andersen sampler were in general higher than those obtained with the RCS. The FSL of samples taken with the Andersen device ranged from 2 to $339 \mathrm{cfu} /$ $\mathrm{m}^{3}$ (mean $=83 \mathrm{cfu} / \mathrm{m}^{3}$ ), while the FSL of samples taken with the RCS instrument ranged from 0 to $169 \mathrm{cfu} / \mathrm{m}^{3}$ (mean $=49 \mathrm{cfu} /$ $\mathrm{m}^{3}$ ). In the Bone Marrow Transplant Unit, 
the only area studied supplied with a HEPA filter, FSL were usually lower (mean FSL with the Andersen sampler $=13 \mathrm{cfu} / \mathrm{m}^{3}$; mean FSL with the RCS $=6 \mathrm{cfu} / \mathrm{m}^{3}$ ) when compared to areas artificially ventilated without HEPA filters (mean FSL with the Andersen sampler $=80 \mathrm{cfu} / \mathrm{m}^{3}$; mean FSL with the RCS $=60 \mathrm{cfu} / \mathrm{m}^{3}$ ). Naturally ventilated areas showed the highest fungal contaminant concentrations (mean FSL with the Andersen sampler $=116 \mathrm{cfu} / \mathrm{m}^{3}$; mean FSL with the RCS $\left.=62 \mathrm{cfu} / \mathrm{m}^{3}\right)$. The most frequently isolated fungal genera in the samples obtained with both devices were Penicillium, Aspergillus and Cladophialophora. Table 1 shows the most prevalent fungal genera in the air samples. It is important to mention that, in the Andersen samples, it was possible to distinguish 28 different fungal genera, while in the RCS samples only seven were identified. Analysis of spore sizes based on particle diameter was conducted on the Andersen samples: $53 \%$ were $<2 \mu \mathrm{m}$, $30 \%$ were $\geq 2 \mu \mathrm{m}$ and $\leq 5 \mu \mathrm{m}$, and $17 \%$ were $>5 \mu \mathrm{m}$. The Pearson correlation coefficient was calculated, revealing a significant correlation between total quantitative measurements of fungal propagules taken with the two devices in each sample (Pearson correlation coefficient $=0.50$ ) (Figure 1).

Although the three most frequently isolated fungal genera were the same in samples taken with both devices, the air samples drawn with the Andersen sampler presented 28 different genera. This finding suggests that this sampler may recover a broader spectrum of fungi, thus being probably superior to the RCS for qualitative assessments of airborne fungal spores.

Both sampling devices showed higher FSL in naturally ventilated areas. In artificially ventilated environments supplied with HEPA filters, lower FSL were generally detected. This finding suggests that these filters may play a protective role in controlling airborne fungal concentrations, which may justify their use in areas occupied by patients at higher risk to develop infections by such agents (18).

Other investigators have evaluated the performance of these two air samplers. Buttner and Stetzenbach (10) found no sig-

Table 1. Fungal genera most frequently isolated with the two air samplers.

\begin{tabular}{lcc}
\hline Genera & \multicolumn{2}{c}{ Number of positive samples (\%) } \\
\cline { 2 - 3 } & $\begin{array}{c}\text { Andersen } \\
\text { sampler }\end{array}$ & RCS \\
\hline Penicillium & $35(83)$ & $39(92)$ \\
Aspergillus & $33(78)$ & $18(42)$ \\
Cladophialophora & $31(73)$ & $20(47)$ \\
Fusarium & $21(50)$ & - \\
Trichoderma & $21(50)$ & - \\
Rhodotorulla & $15(35)$ & - \\
Alternaria & $15(35)$ & - \\
Candida & - & $14(33)$ \\
Rhizopus & - & $9(21)$ \\
Number of samples & 42 & 42 \\
\hline
\end{tabular}

RCS: Reuter centrifugal air sampler.

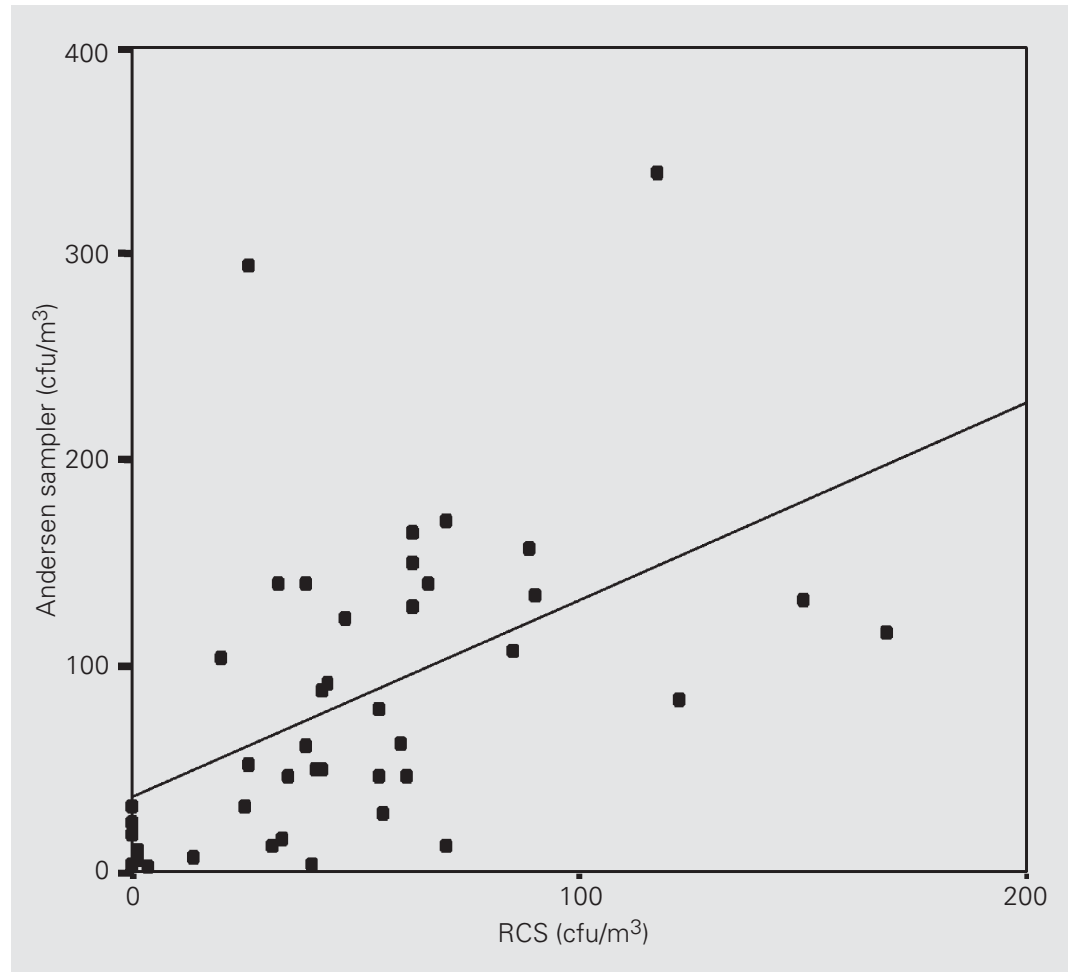

Figure 1. Correlation between fungal spore levels determined by measurement with the N-6 Andersen sampler and the Reuter centrifugal air sampler (RCS) 
nificant difference between number of fungal spore data collected with these devices. Smid et al. (11) showed a superior quantitative efficiency of the N-6 Andersen air sampler and concluded that measurements made with the N-6 Andersen and the RCS instruments did not correlate. Verhoeff et al. (16) also reported a low correlation coefficient between measurements of fungal propagules taken with these air samplers. Some investigators $(19,20)$ stated that the efficiency of the RCS device increases when the particles collected are larger than $2 \mu \mathrm{m}$. In the present study, although $53 \%$ of the fungal propagules were smaller than $2 \mu \mathrm{m}$ in diameter, we found a significant correlation between the number of particles taken with the two instruments. These results suggest that the RCS is probably an acceptable instrument to perform quantitative studies of airborne fungal propagules, as long as all readings are made with the same device over a period of time. For qualitative studies, however, this device may not be recommended.

\section{Acknowledgments}

We wish to thank the Infection Control Group of Hospital das Clínicas for their collaboration.

\section{References}

1. Hoffman RE, Wood RC \& Kreiss K (1993). Building related asthma in Denver office workers. American Journal of Public Health, 83: 8993.

2. Hodgson MJ, Morey P, Leung WY, Morrow L, Miller D, Jarvis BB, Robbins H, Halsey JF \& Storey E (1998). Building-associated pulmonary disease from exposure to Stachybotrys chartarum and Aspergillus versicolor. Journal of Occupational and Environmental Medicine, 40: $241-249$

3. Cooley JD, Wong WC, Jumper CA \& Straus DC (1998). Correlation between the prevalence of certain fungi and Sick Building Syndrome. Occupational and Environmental Medicine, 55: 579-584.

4. Rotstein C, Cummings KM, Tidings J, Killion K, Powell E, Gustafson TL \& Higby D (1985). An outbreak of invasive aspergillosis among allogeneic bone marrow transplants: a case-control study. Infection Control and Hospital Epidemiology, 6: 347-355.

5. Gerson SL, Talbot GH, Hurwitz S, Strom BL, Lusk EJ \& Cassileth PA (1984). Prolonged granulocytopenia: the major risk factor for invasive pulmonary aspergillosis in patients with acute leukemia. Annals of Internal Medicine, 100: 345-351.

6. Arnow PM, Sadigh M, Costas C, Weil D \& Chudy R (1991). Endemic and epidemic aspergillosis associated with in-hospital replication of aspergillus organisms. Journal of Infectious Diseases, 164: 9981002.

7. Gambale W, Purchio A \& Paula CR (1983). Periodicidade diária de fungos anemófilos na cidade de São Paulo, Brasil. Revista de Microbiologia, 12: 176-181.

8. Gambale W, Purchio A \& Paula CR (1983). Influência de fatores abióticos na dispersão aérea de fungos na cidade de São Paulo, Brasil. Revista de Microbiologia, 14: 204-214.

9. Kozak Jr PP, Gallup J, Cummins LH \& Gillman SA (1979). Factors of importance in determining the prevalence of indoor moulds. Annals of Allergy, 43: 88-94.

10. Buttner MP \& Stetzenbach LD (1993). Monitoring airborne fungal spores in an experimental indoor environment to evaluate sampling methods and the effects of human activity on air sampling. Applied and Environmental Microbiology, 59: 219-226.

11. Smid T, Schokkin E, Boleij JSM \& Heederik D (1989). Enumeration of viable fungi in occupational environments: a comparison of samplers and media. American Industrial Hygiene Association Journal, 50: 235-239.

12. Burge HP, Boise JR, Rutherford JA \& Solomon WR (1977). Comparative recoveries of airborne fungus spores by viable and nonviable modes of volumetric collection. Mycopathologia, 61: 27-33.

13. Miller JD \& Young JC (1997). The use of ergosterol to measure exposure to fungal propagules in indoor air. American Industrial Hygiene Association Journal, 58: 39-43.

14. Jensen PA, Todd WF, Davis GN \& Scarpino PV (1992). Evaluation of eight bioaerosol samplers challenged with aerosols of free bacteria. American Industrial Hygiene Association Journal, 53: 660-667.

15. Nesa D, Lortholary J, Bouakline A, Bordes M, Chandenier J, Derouin F \& Gangneux JP (2001). Comparative performance of impactor air samplers for quantification of fungal contamination. Journal of Hospital Infection, 47: 149-155.

16. Verhoeff AP, Van Wijnen JH, Boleij JSM, Brunekreef B, van ReenenHoekstra ES \& Samson RA (1990). Enumeration and identification of airborne viable mould propagules in houses. Allergy, 45: 275-284.

17. Ridell RW (1950). Permanent stained mycological preparations obtained by slide culture. Mycologia, 42: 265 .

18. Streifel AJ (1999). Design and maintenance of hospital ventilation systems and the prevention of airborne nosocomial infections. In: Mayhall CG (Editor), Hospital Epidemiology and Infection Control. 2nd edn. Lippincott Williams \& Wilkins, Philadelphia, PA, USA.

19. Clark S, Lach V \& Lidwell OM (1981). The performance of the Biotest RCS centrifugal air sampler. Journal of Hospital Infection, 2 : 181-186.

20. Macher JM \& First MW (1983). Reuter centrifugal air sampler: measurement of effective airflow rate and collection efficiency. Applied and Environmental Microbiology, 45: 1960-1962. 